\title{
FATORES DE RISCO RELACIONADOS À INFECÇÃO DO TRATO URINÁRIO NA ASSISTÊNCIA À SAÚDE
}

\author{
RISK FACTORS RELATED TO URINARY TRACT INFECTION IN HEALTH CARE
}

\author{
Francisco Eudison da Silva Maia ${ }^{\mathbf{a}^{*}}$, Anne Itamara Benigna Evangelista ${ }^{* *}$, \\ Alcivan Nunes Vieira* \\ aeudisonmaia@yahoo.com.br \\ *Universidade Potiguar - Mossoró (RN), Brasil \\ **Universidade do Estado do Rio Grande do Norte - Mossoró (RN), Brasil
}

Data de recebimento do artigo: 10/12/2014

Data de aceite do artigo: 04/08/2015

\section{RESUMO}

Esta pesquisa tem como objetivo identificar os fatores de risco para a ocorrência da infecção do trato urinário relacionada à atenção à saúde. Trata-se de uma revisão integrativa da literatura, realizada a partir de artigos publicados na Biblioteca Virtual em Saúde (BVS) de abril a junho de 2012. Utilizaram-se os seguintes descritores: "sistema urinário", "bexiga urinária" e "fatores de risco". Os principais fatores de risco associados à infecção do trato urinário, na atenção à saúde, são: a condição patológica prévia; a hospitalização; indicação indevida da cateterização; os cuidados com o cateter; o tempo de permanência do cateter; o sexo e a idade do paciente. A sondagem vesical é um dos principais fatores de risco para a ocorrência da infecção e, em geral, o mais lembrado. Entretanto, existem outros fatores que precisam ser levados em consideração pelos profissionais de saúde. A partir da sua identificação, será possível adotar medidas eficazes de prevenção e controle.

Palavras-chave: Enfermagem; infecção hospitalar; unidades de terapia intensiva.

\section{ABSTRACT}

This research aimed to identify risk factors for the occurrence of urinary tract infection related to health care. It is an integrative literature review of articles published in Biblioteca Virtual em Saúde (BVS) from April to June 2012. The following descriptors were used: "sistema urinário", "bexiga urinária" and "fatores de risco" ["urinary tract", "urinary blatter" and "risk factors"]. The main risk factors associated with urinary tract infection in health care are: prior pathological condition; hospitalization; indication of improper catheterization; care of the catheter; the catheter dwell time; sex and age of patient. The catheterization is a major risk factor for the occurrence of the infection and generally the most remembered. However, there are other factors that need to be taken into account by health professionals. By identifying these factors, professionals can take effective measures of prevention and control.

Keywords: Nursing; cross infection; intensive care units. 


\section{Introdução}

A Infecção Hospitalar (IH) consiste em uma das mais frequentes e importantes complicaçóes dos pacientes submetidos à hospitalização. É definida como uma infecção localizada ou sistêmica, contraída dentro de uma unidade de saúde ou durante a hospitalização. Portanto, é consequência de uma reação adversa à presença de um agente infeccioso ou à produção de suas toxinas ${ }^{1}$.

A patologia em questão está presente em todo o mundo e representa um grave problema de saúde pública, uma vez que constitui uma das principais causas de morbimortalidade de pessoas que se encontram no ambiente hospitalar. O problema pode ser minimizado por meio da adoçáo de medidas de prevenção e controle por parte de todos os profissionais que atuam na assistência à saúde 2 .

Até o ano de 2008, o conceito de Infecçóes Hospitalares adotado pelo Ministério da Saúde do Brasil enfocava primordialmente infecçóes que ocorriam no espaço hospitalar ${ }^{3}$. O conceito foi revisado e a nova terminologia foi adotada, passando a abranger as Infecçôes Relacionadas à Assistência em Saúde (IrAS). Essa nova nomenclatura compreende todas as infecçóes adquiridas por meio da atenção à saúde, seja pela realização de procedimentos ambulatoriais, pela atençáo prestada em domicílio ou durante a internaçáo hospitalar ${ }^{4}$.

O conceito de IrAS amplia o entendimento de que as infecçôes se restringem àquelas que ocorrem essencialmente no ambiente hospitalar, considerando que, na realidade, podem ocorrer em todos os níveis assistenciais, seja na unidade básica de saúde, hospital, domicílio ou serviços de home caré .

Entre as IrAS, a Infecção do Trato Urinário (ITU) é a mais comum em qualquer hospital do mundo, chegando a corresponder a cerca de $40 \%$ do total das IrAS em determinados hospitais ${ }^{5-6}$. A ITU relacionada à assistência à saúde é caracterizada pela invasão do trato urinário superior ou inferior por micro-organismos em decorrência de procedimentos invasivos, como a sondagem vesical ${ }^{7}$.

Os sinais e sintomas associados à infecção urinária incluem polaciúria, urgência miccional, disúria, alteração na coloração e no aspecto da urina com surgimento de urina turva acompanhada de alteraçóes no sedimento urinário, hematúria e piúria. É comum a ocorrência de dor abdominal na topografia do hipogástrio (projeção da bexiga) e no dorso (projeção dos rins), cursando com febre ${ }^{7}$. A ITU pode comprometer somente o trato urinário baixo, caracterizando o diagnóstico de cistite, ou afetar simultaneamente o trato urinário inferior e o superior, configurando infecção urinária alta, também denominada pielonefrite?

Quando a ITU é adquirida no ambiente hospitalar, em paciente internado, os agentes etiológicos são bastante diversificados, predominando as enterobactérias, com redução na frequência de E. coli (embora ainda permaneça habitualmente como a primeira causa), e um crescimento de Proteus sp, Pseudomonas aeruginosa, Klebsiella sp., Enterobacter sp., Enterococcus faecalis e de fungos, com destaque para Candida $s p^{8,9}$.

Embora a morbidade e a mortalidade de ITU sejam consideradas relativamente baixas em comparação a outras IrAS, esse tipo de infecção tem repercussôes na assistência à saúde, seja pelo aumento nos gastos para seu tratamento, seja pela possibilidade de provocar complicaçóes ${ }^{10}$.

Existem diversos fatores de risco para a ocorrência desse tipo de infecção, tanto relacionados ao próprio paciente quanto à assistência à saúde ou à instrumentalização do trato urinário. Ambos têm seu impacto na ocorrência de uma ITU, embora a ênfase geralmente seja dada à alta prevalência da instrumentalização ${ }^{6}$.

Este estudo tem como objetivo identificar, a partir da literatura, os fatores de risco para a ocorrência de ITU relacionada à assistência à saúde. Para alcançar o objetivo proposto foi realizada uma revisão integrativa da literatura, em publicações disponíveis na Biblioteca Virtual em Saúde. Justifica-se pela necessidade do conhecimento como ferramenta estratégica para a elaboração de açōes de prevenção em relação às ITU na assistência à saúde. Desse modo, esta pesquisa contribui de forma somatória às discussōes sobre o tema, fomentando a relevância da intervenção adequada dos profissionais da saúde na melhora da qualidade de vida da população.

\section{Metodologia}

Trata-se de uma revisão integrativa da literatura, método que consiste na síntese de um determinado assunto a partir da literatura já publicada, podendo identificar a necessidade da realização de novos estudos, como também de reflexôes sobre melhorias na prática clínica ${ }^{11,12}$.

O levantamento bibliográfico foi realizado por meio da Biblioteca Virtual de Saúde (BVS), nas bases de dados do SciELO (Scientific Electronic Library Online), LILACS (Literatura Latino Americana e do Caribe em Ciências da Saúde) e MEDLINE (Medical Literature Analysis and Retrieval System Online). Foram incluídos artigos completos publicados na língua portuguesa, sem delimitação de período de publicação. Esta pesquisa foi realizada no período de abril a junho de 2012.

Para construir este manuscrito foram seguidas as seguintes etapas: o estabelecimento das questões e objetivos da revisão integrativa; estabelecimento dos critérios de inclusão e exclusão de artigos; definição das informações a serem extraídas dos artigos selecionados; análise dos resultados; discussão e apresentação dos resultados; e, por último, a apresentação da revisão ${ }^{13}$. Seu desenvolvimento teve como base a seguinte questão norteadora: 
que fatores de riscos estão implicados na infecção do trato urinário relacionada à atenção à saúde?

Para a delimitaçáo dos artigos, foram utilizados como critérios de inclusão: que investigasse ou relatasse os fatores associados à ocorrência da infecção do trato urinário; estar disponível no idioma português. Foram excluídos da amostra os editoriais e as cartas ao editor, pelo entendimento de que esse modelo de texto não disponibilizava informaçóes suficientes para o alcance dos objetivos propostos.

Utilizou-se a seguinte estratégia de busca: cruzamento das palavras chave "Infecção do Trato Urinário", "sondagem vesical" e "fatores de risco" com os descritores "Sistema Urinário", "Bexiga Urinária" e "Fatores de Risco". Após a aplicação desses critérios, a busca resultou em 128 publicaçôes, das quais, após a aplicação dos critérios de inclusão, 88 foram eliminadas, restando 40 artigos (conforme Quadro 1). No momento exploratório, foram empreendidas leituras dos resumos dos artigos, evitando concomitantemente aqueles duplicados e indexados em mais de uma base. Do montante dos 40, 9 foram utilizados, sendo $7^{1,7,9,10,11,15,17}$ oriundos da base de dados SciELO, $1^{2}$ da LILACS e $1^{6}$ da MEDLINE. Esses $9^{1,2,6,7,9,10,11,15,17}$ foram utilizados para constituir o corpus da discussão por apresentarem maior afinidade com o tema proposto.

\section{Resultados}

O Quadro 1 apresenta os artigos encontrados em periódicos e bases de dados da BVS.

Após a leitura seguindo a sistematização organizacional conforme a metodologia proposta, foi delimitada na literatura estudada os seguintes fatores de risco para a ocorrência da infecção urinária relacionada à atenção à saúde, a saber: condição patológica prévia, hospitalização, indicação indevida da cateterizaçáo, cuidados com o cateter, tempo de permanência, sexo e idade i,6,7,14-19. $^{4}$.

\section{Discussão}

\section{Condições patológicas prévias para ocorrên- cia da ITU}

Com relação às condiçóes patológicas prévias, que consistem em condiçóes que antecedem e possuem relação direta com a ocorrência da infecção, os fatores de risco para ITU estão relacionados à assistência em saúde e diferem dos que estão presentes nas infecçóes comunitárias. Nestas, os fatores de risco estão relacionados principalmente à predisposiçáo do paciente, ao passo que nas ITU relacionadas à atenção à saúde podem estar associados aos pacientes ou procedimentos diagnósticos e terapêuticos ${ }^{15}$.

Um exemplo das patologias prévias que atuam como fatores de risco para a ocorrência da ITU são as condiçóes que provocam um esvaziamento incompleto da bexiga, como as anormalidades anatômicas ou fisiológicas, as más formaçōes congênitas, o estreitamento uretral, a hipertrofia prostática, o divertículo de bexiga, a cistocele e o refluxo vesicoureteral. Incluem-se ainda as patologias neurológicas e obstrutivas devido à existência de cálculos ${ }^{7}$.

Quadro 1: Distribuição e quantidade de artigos por periódicos e bases de dados com respectivas áreas temáticas e ano de publicação.

\begin{tabular}{|c|c|c|c|}
\hline Periódico/BD & Qa & Ap & At \\
\hline $\begin{array}{c}\text { Revista Latino-americana de } \\
\text { Enfermagem /SciELO }\end{array}$ & 2 & $1996 / 2010$ & Enfermagem \\
\hline $\begin{array}{c}\text { Revista Associaçáo Medica } \\
\text { Brasileira/SciELO }\end{array}$ & 6 & $2004 / 2004 / 2007$ & Medicina \\
\hline $\begin{array}{c}\text { Revista Brasileira Ginecologia e } \\
\text { Obstetrícia/SciELO }\end{array}$ & 1 & 2002 & Medicina \\
\hline $\begin{array}{c}\text { Arquivos Catarinenses de } \\
\text { Medicina/LILACS }\end{array}$ & 3 & $2003 / 2003$ & Medicina \\
\hline $\begin{array}{c}\text { Jornal de Pediatria/SciELO } \\
\text { endoscopia digestiva/SciELO }\end{array}$ & 1 & 2005 & Medicina \\
\hline $\begin{array}{c}\text { Jornal Brasileiro de Patologia } \\
\text { Médica/SciELO }\end{array}$ & 3 & $2005 / 2005 / 2009$ & Medicina \\
\hline $\begin{array}{c}\text { Revista Brasileira de Análises } \\
\text { Clínicas/LILACS }\end{array}$ & 11 & $12009 / 2009 / 2010 / 2011 / 2011$ & Farmácia \\
\hline $\begin{array}{c}\text { Revista Panamericana de } \\
\text { Infectologia/SciELO }\end{array}$ & 1 & 2005 & Medicina \\
\hline
\end{tabular}


Quadro 1: Continuação.

\begin{tabular}{|c|c|c|c|}
\hline Periódico/BD & Qa & Ap & At \\
\hline Acta Médico/MEDLINE & 1 & 2006 & Medicina \\
\hline $\begin{array}{c}\text { Revista Brasileira Saúde } \\
\text { Materno Infantil/SciELO }\end{array}$ & 1 & 2007 & Medicina \\
\hline $\begin{array}{c}\text { Revista Brasileira de } \\
\text { Enfermagem/SciELO }\end{array}$ & 1 & 2007 & Medicina \\
\hline $\begin{array}{c}\text { Revista Brasileira de Terapia } \\
\text { Intensiva/SciELO }\end{array}$ & 1 & 2007 & Medicina \\
\hline $\begin{array}{c}\text { J Obstet Gynaecol Res/ } \\
\text { MEDLINE }\end{array}$ & 1 & 2007 & Enfermagem \\
\hline $\begin{array}{c}\text { Ciência, Cuidado e Saúde/ } \\
\text { LILACS }\end{array}$ & 1 & 2007 & Medicina \\
\hline $\begin{array}{c}\text { Revista Paranaense de Medicina/ } \\
\text { SciELO }\end{array}$ & 1 & 2010 & Medicina \\
\hline $\begin{array}{c}\text { Revista Brasileira de Clinica } \\
\text { Médica/LILACS }\end{array}$ & 1 & 2011 & 2011 \\
\hline $\begin{array}{c}\text { Revista da Escola de } \\
\text { Enfermagem da USP/SciELO }\end{array}$ & 1 & Enfermagem \\
\hline \begin{tabular}{c} 
Texto e Contexto/SciELO \\
\hline
\end{tabular}
\end{tabular}

Fonte: Biblioteca Virtual de Saúde.

\section{Os aspectos da ITU no meio hospitalar}

Quanto à hospitalização, os pacientes internados em instituiçóes de saúde estão expostos à colonização por parte de uma ampla variedade de micro-organismos patogênicos, principalmente em Unidade de Terapia Intensiva (UTI), pois nesse setor o uso de antimicrobianos potentes e de largo espectro e os procedimentos invasivos são rotineiros, incluindo a cateterização vesical ${ }^{15}$.

Salienta-se que o ambiente hospitalar é inevitavelmente um grande reservatório de patógenos oportunistas, de modo que as infecçóes hospitalares podem ser adquiridas náo apenas por pacientes, que apresentam maior susceptibilidade, mas também, embora menos frequentemente, por visitantes e funcionários do próprio hospital ${ }^{15}$.

A maioria dos casos de ITU relacionada à atenção à saúde em instituiçóes hospitalares ocorre após cateterização do trato urinário. Cerca de $80 \%$ das ITU no ambiente hospitalar são associadas ao uso de cateter vesical, e entre $5 \%$ e $10 \%$ sáo causados por outras manipulaçôes da área. Aproximadamente $10 \%$ dos pacientes são cateterizados durante internação hospitalar, com uma permanência média de 4 dias ${ }^{10,11}$.

Os pacientes sondados cronicamente fora do ambiente hospitalar possuem um risco de infecção consideravelmente inferior. Os pacientes internados, além de intrinsecamente mais vulneráveis à infecção, são expostos a outros fatores de risco, tais como: procedimentos invasivos, cirurgias complexas, drogas imunossupressoras, antimicrobianos e interaçôes com a equipe de saúde e os fômites ${ }^{1}$.

Outro fator de risco identificado foi a indicação indevida da cateterização. Existe um conjunto de indicaçôes que devem ser consideradas antes de uma cateterização vesical, que objetivam estabelecer critérios para a realização do procedimento, visando a evitar o uso indevido ${ }^{7}$. Entre essas indicaçôes estão as condições em que o paciente apresenta retenção urinária de forma aguda, relacionada concomitantemente ao uso de anestésicos em cirurgias ou à sedação, prévia à realização de alguns procedimentos invasivos. Incluemse ainda nesse nicho os traumas envolvendo o trato urinário ${ }^{7}$.

Outra indicação é a presença de obstruções crônicas da via urinária, tais como a estenose uretral, hiperplasia prostática obstrutiva e tumores. Nesse caso, a cateterização crônica é indicada com o intuito de assegurar a eliminação vesical sem provocar desconforto ou dor no paciente ${ }^{2,9}$.

A cateterização vesical também é indicada em situaçóes que necessitem de controle preciso de débito urinário, por exemplo em pacientes com instabilidade hemodinâmica em UTI, ou durante os procedimentos cirúrgicos no período perioperatório, com o intuito de assegurar a asepssia do procedimento ${ }^{6}$. Finalmente, seu uso é indicado em pacientes que requerem imobilização 
prolongada (fraturas pélvicas; lesóes potencialmente instáveis da coluna torácica ou lombar), ou aqueles que, dentro ou fora dos serviços de saúde, possuem sequelas de injúrias neurológicas que implicam em limitação de movimentos espontâneos ${ }^{10,11}$.

Conterno et al. ${ }^{17}$ relataram em sua pesquisa que 13\% dos pacientes tiveram a indicação da cateterização vesical considerada inapropriada, e em $41 \%$ a manutenção foi além do período necessário. A indicação indevida da cateterização favorece a ocorrência de ITU, pois implica exposição do paciente a um procedimento invasivo com potenciais riscos para a ocorrência de infecçáo ${ }^{17}$.

Antes da decisão por uma cateterização vesical, alguns serviços preconizam a adoção de medidas não invasivas que tentam estimular a micção espontânea em pacientes que apresentam essa possibilidade, as quais consistem em técnicas alternativas, como proporcionar um ambiente privativo e confortável, induzir o paciente a ouvir barulho de água corrente, mergulhar as mãos em água aquecida, irrigar o períneo com água aquecida e aplicar compressas quentes na regiấo suprapúbica ${ }^{2}$.

A ausência dos cuidados com o cateter emerge enquanto um fator de risco importante quanto à própria cateterização. Essa categoria de cuidados abrange desde o procedimento de inserçáo até os cuidados desenvolvidos para a manutenção do cateter, os quais preservam a assepsia do local, bem como dos dispositivos que compóe o sistema de drenagem ${ }^{7}$.

Os cuidados preconizados com o intuito de preservar assepticamente os cateteres urinários são a inserção asséptica do cateter urinário e a manutenção do sistema de drenagem fechado. Em caso de desconexão, deve-se substituir o cateter e sistema de coleta e assegurar que o fluxo de urina esteja desobstruindo o cateter, mantendo-o junto do tubo coletor, livre de dobras ${ }^{7}$.

A inserção do cateter é considerada um procedimento invasivo que deve ser realizado em condições assépticas, em que o uso das precauçôes padrão é obrigatório ${ }^{2}$.

Entre os cuidados imprescindíveis para a prevenção de infecçôes destacam-se: higienizar as mãos com água e sabão todas as vezes em que for haver manipulação da sonda; realizar higiene local pelo menos uma vez ao dia com água e sabão; não usar pomadas com antibióticos ou antissépticos na área periuretral nas higienizaçôes de rotina; esvaziar a bolsa coletora sempre que estiver com dois terços de sua capacidade preenchida; manter o fluxo contínuo e evitar refluxo de urina ${ }^{11}$.

Em relação ao sistema coletor, algumas condutas são imprescindíveis à prevenção de infecção. A primeira delas é manter em todos os momentos o coletor abaixo do nível da bexiga; não colocar em hipótese alguma o coletor no chão; esvaziá-lo regularmente usando um recipiente limpo para a coleta e individualizado para cada paciente. Ao realizar o procedimento deve-se evitar falar, tossir ou espirrar, assim como o contato da torneira de drenagem com o recipiente de coleta ${ }^{15}$.

\section{Prevalência da ITU na assistência à saúde}

Estima-se que entre 17 e 69\% das ITU associadas ao cateter possam ser prevenidas com medidas de controle de infecção recomendadas, o que significa que até 380 mil infecçóes e 9 mil mortes relacionadas com ITU por ano poderiam ser prevenidas ${ }^{7}$.

O tempo de permanência da sondagem vesical é um importante fator de risco para a ocorrência da ITU: quanto mais prolongado, maior a colonização local e o risco de infecção?. Sáo classificados como de curta permanência (1 a 7 dias) em pacientes pós-operados, de média permanência (7 a 30 dias) em pacientes criticamente enfermos e de longa permanência (mais de 30 dias) em pacientes com continência ou obstrução urinária $^{19}$. A sondagem urinária por período superior a sete dias é associada ao desenvolvimento de ITU em até $25 \%$ dos pacientes, com risco diário de 5\% $\%^{7,9,15}$. Portanto, a duração do cateterismo é, provavelmente, o fator de risco mais importante para a instalação da bacteriúria relacionada ao cateter vesical de demora ${ }^{1}$. Mesmo com o sistema de drenagem fechado, a bacteriúria ocorre inevitavelmente ao longo do tempo através de interrupçóes no sistema de estéril ou da route extraluminal ${ }^{7}$. Nesse sentido, é necessário questionar a real necessidade da permanência da cateterização vesical ${ }^{10,11}$.

Quanto ao sexo e à idade, as ITU acometem homens e mulheres em qualquer faixa etária, no entanto, incidem em maior frequência em mulheres. Essa condição deve-se a alguns fatores intrínsecos ao sistema urinário feminino quando relacionado ao masculino, como a extensão da uretra e a colonização da região periuretral ${ }^{15}$. Evidências indicam que os grupos de pessoas com maior risco para ITU e decorrente óbito são as mulheres, idosos e os pacientes com imunidade comprometida ${ }^{7}$.

A prevalência de ITU aumenta em homens com idade acima de 50 anos, provavelmente devido à hipertrofia da próstata e instrumentação do trato urinário inferior que é mais frequente nessa faixa etária ${ }^{11}$.

Em relação à faixa etária, as doenças infecciosas representam uma ameaça significativa de morbidade e mortalidade às pessoas idosas devido ao comprometimento das defesas do hospedeiro provocada por uma redução na imunidade celular e humoral ${ }^{2}$. A perda da reserva fisiológica relacionada à idade e às doenças crônicas também contribui para o aumento da susceptibilidade, sendo a ITU uma das infecçóes mais comuns observadas na pessoa idosa. A condiçáo natural de ser idoso por si só é considerada fator de risco para a ocorrência de uma ITU relacionada à assistência à saúde ${ }^{7}$. 
Nesse diapasão, pode-se concluir que a sondagem vesical é um dos principais fatores de risco para a ocorrência da ITU, ou o mais apontado pela literatura. Entretanto, outros fatores de risco estão presentes na ocorrência da infecçáo. Sendo assim, a equipe de profissionais em saúde precisa estar ciente desses fatores para a adoção de medidas de prevenção e controle eficazes.

\section{Conclusão}

Os principais fatores de risco associados à infecção do trato urinário na atenção à saúde, a partir da literatura pesquisada, são: a condição patológica prévia do paciente e suas implicaçóes na imunidade celular e/ ou inespecífica; a própria hospitalização, que por sua vez expõe o paciente a várias alterações em sua vida, como nos hábitos alimentares, na ingesta hídrica e até mesmo nos hábitos de higiene; a indicação indevida da cateterizaçáo, capaz de aumentar exponencialmente o risco; os cuidados com o cateter, cuja execução compete principalmente à equipe de enfermagem; o tempo de permanência do cateter; o sexo e a idade do paciente.

Esta revisão demonstrou que a sondagem vesical é um dos principais fatores de risco para a ocorrência ITU, e, em geral, o mais apontado pela literatura analisada. Entretanto, existem outros fatores que precisam ser levados em consideração pelos profissionais de saúde, como as condiçóes patológicas prévias.

\section{Referências}

1. Jacquier NM, Santos L, Centeno JH. Uma olhada qualitativa sobre o cuidado integral em Infecçóes Hospitalares. Rev Rene. 2008;9(2):138-47.

2. Queirós MI. Infecçôes urinárias e uso de cateter vesical de demora em unidade pediátrica. Rev Rene. 2011;12(2):295-301.

3. Brasil. Ministério da Saúde. Portaria no 2.616, de 12 de maio de 1998. Regulamenta as açóes de controle de infecção hospitalar no país, em substituição a Portaria MS 930/92. Brasília: Ministério da Saúde; 1998. [acesso em 22 abr. 2012]. Disponível em: <http://www.anvisa.gov.br/servicosaude/controle/aula_SINAIS.pdf $>$.

4. Medeiros EAS. Infecção Relacionada à Assistência à Saúde. São Paulo; 2012. [acesso em 22 abr. 2012]. Disponível em: $<$ http://www.iras.org.br/index.htm>.

5. Rodrigues EAC, Richtmann R. IRAS: Infecçóes Relacionadas à Assistência à Saúde: Orientaçôes práticas. São Paulo: Sarvier; 2008.
6. Kamilya G, Seal SL, Mukherji J, Bhattacharyya SK, Hazra A. A randomized controlled trial comparing short versus long-term catheterization after uncomplicated vaginal prolapse surgery.J Obstet Gynaecol Res. 2010;36(1):154-8.

7. Roriz-filho JS, Vilar FC, Mota LM, Leal CL, Pisi PCB. Infecção do trato urinário. Simpósio: Condutas em enfermaria de clínica médica de hospital de média complexidade - Parte 1 Capítulo III. Rev Med de Ribeirão Preto. 2010;43(2):118-25.

8. Peleg AY, Hooper DC. Hospital-Acquired Infections Due to Gram-Negative Bacteria. N. Engl J Méd. 2010;362(19):1804-13.

9. Oliveira R, Maruyama SAT. Controle de infecção hospitalar: histórico e papel do estado. Rev. Eletr. Enf. 2008;10(3):775-83.

10. Mazzo A, Godoy S, Alves LM, Mendes IAC, Trevizan MA, Rangel EML, et al. Cateterismo urinário: facilidades e dificuldades relacionadas à sua padronização. Texto contexto. 2011; 20(2):333-39.

11. Guimarães JAF, Aquino PS, Pinheiro AKB, Moura JG. Pesquisa Brasileira sobre prevençáo do câncer de colo uterino: uma revisão integrativa. Rev Rene. 2012;13(1):220-30.

12. Polit DF, Beck CT. Essentials of nursing research. Methods, appraisal and utilization. Philadelphia (USA): Lippincott Williams \& Wilkins. 2006. p.457-94.

13. Mendes KDS, Silveira RCCP, Galvão CM. Revisão integrativa: método de pesquisa para a incorporação de evidências na saúde e na enfermagem. Texto Contexto Enferm. 2008; 17 (4):758-64.

14. Oliveira AC. Infecções Hospitalares: Epidemiologia, Prevenção e Controle. Rio de Janeiro: Guanabara Koogan; 2009.

15. Moura MEB. Infecção hospitalar: estudo de prevalência em um hospital público de ensino. Rev Bras Enferm. 2007;60(4):416-21.

16. Kuga APV, Fernandes MVL. Prevenção de Infecção do Trato Urinário (ITU) Relacionado à Assistência à Saúde. 2a ed. São Paulo: APECIH; 2009.

17. Conterno LO, Lobo JA, Masson W. Uso excessivo do cateter vesical em pacientes internados em enfermarias de hospital universitário. Rev Esc Enferm USP. 2011;45(5):1089-96.

18. Brunner B. S; Suddarth S. Tratado de Enfermagem Médico - Cirúrgica. Rio de Janeiro: Guanabara Koogan; 2009.

19. Couto RC, Pedrosa TMG. Guia Prático de Controle de Infecção Hospitalar: Epidemiologia, Controle e Tratamento. $2^{\mathrm{a}}$ ed. Rio de Janeiro: Guanabara Koogan; 2009.

\section{Como citar este artigo:}

Maia FES, Evangelista AIB, Vieira NA. Fatores de risco relacionados à infecção do trato urinário na assistência à saúde. Rev. Aten. Saúde. 2015;13(46):5-10 